PSI UNISC

Recebido em: 11/05/2019

Autor para contato: carlos.naujorks@ufsc.br
ISSN: $2527-1288$

Aceito em: 21/01/2020

doi: $10.17058 /$ psiunisc.v4i1.13532

\title{
Intervenção Institucional na Educação de Jovens e Adultos: um Relato de Experiência
}

Intervención Institucional en la Educación de Jóvenes y Adultos: un Relato de Experiencia Institutional Intervention in Youth and Adult Education: an Experience Report

Leandro Castro Oltramari

ORCID: https://orcid.org/0000-0002-9610-0502 Universidade Federal de Santa Catarina, Santa Catarina/Brasil

Carlos José Naujorks

ORCID: https://orcid.org/0000-0003-0258-1585

Universidade Federal de Santa Catarina, Santa Catarina/Brasil

Declaração de Direito Autoral

A submissão de originais para este periódico implica na transferência, pelos autores, dos direitos de publicação impressa e digital. Os direitos autorais para os artigos publicados são do autor, com direitos do periódico sobre a primeira publicação. Os autores somente poderão utilizar os mesmos resultados em outras publicações indicando claramente este periódico como o meio da publicação original. Em virtude de sermos um periódico de acesso aberto, permite-se o uso gratuito dos artigos em aplicações educacionais e científicas desde que citada a fonte conforme a licença CC-BY da Creative Commons.

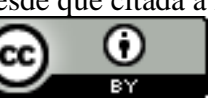

Creative Commons Atribuição 4.0 Internacional.

\section{Resumo}

O presente trabalho é um relato de experiência, desenvolvido a partir de um projeto de extensão realizado com um grupo de dez coordenadores de núcleo de Educação de Jovens e Adultos (EJA) de um município da Região Metropolitana de Florianópolis (SC), ao longo dos anos de 2016 e 2017. Ele foi referenciado em autores como Lourau (1995; 2004), Lapassade (1983), Guirado (2004) e Machado e Sayão (2017). A intervenção teve como dispositivo metodológico o Plantão Institucional (PI) (Lerner, Fonseca \& Machado, 2014). Ele acontecia em um dia de reunião da equipe de trabalho, com os coordenadores de Núcleos e era realizado uma vez por mês, com cerca de três ou quatro encontros por semestre. O número de encontros variou devido às demandas e situações específicas apresentadas no andamento do trabalho. As atividades foram realizadas no Serviço de Atenção Psicológica da Universidade Federal de Santa Catarina (SAPSI) e duravam cerca de uma hora e meia a duas horas e contavam com uma média de seis a oito coordenadores por encontro. Os resultados identificaram que os coordenadores se colocavam em um lugar de protagonismo em relação à EJA como um dispositivo pedagógico e formativo, tomando-se como responsáveis pela implementação e efetivação de seus objetivos. Esbarravam, porém, em inúmeras dificuldades organizacionais e pedagógicas para a realização do trabalho. A sobreimplicação surgia como recurso para lidar com essas dificuldades, através do engajamento e da militância.

Palavras-chaves: Educação de jovens e adultos; Psicologia Institucional; Plantão Institucional.

\section{Resumen}

El presente trabajo es un informe de experiencia, desarrollado a partir de un proyecto de extensión realizado con un grupo de diez coordinadores de núcleo de Educación de Jóvenes y Adultos (EJA) de un municipio de la región metropolitana de Florianópolis (SC - Brasil), a lo largo de los años 2016 y 2017. Fue mencionado en autores como Lourau (1995; 2004), Lapassade (1983), Guirado (2004) y Machado y Sayão (2017). La intervención tuvo como dispositivo metodológico el Guardia Institucional (PI) (Lerner, Fonseca \& Machado, et al, 2014). El PI ocurría en un día de reunión del 
equipo de trabajo, con los coordinadores de Núcleos y se realizaba una vez al mes, con cerca de tres o cuatro encuentros por semestre. El número de encuentros varió debido a las demandas y situaciones específicas que se presentaban a lo largo del progreso del trabajo. Las actividades se realizaron en el Servicio de Atención Psicológica de la Universidad Federal de Santa Catarina (SAPSI) y duraban cerca de una hora y media a dos horas y contaban con una media de seis a ocho coordinadores por encuentro. Los resultados identificaron que los coordinadores se colocaban en un lugar de protagonismo en relación a la EJA como un dispositivo pedagógico y formativo, asumiendo como responsables de la implementación y efectividad de sus objetivos. Sin embargo, a menudo se veían numerosas dificultades organizativas y pedagógicas para la realización del trabajo. La sobreimpliación surgía como recurso para lidiar con esas dificultades, a través del compromiso y de la militancia.

Palabras claves: Educación de jóvenes y adultos; Psicología Institucional; Guardia Institucional.

\begin{abstract}
The present work is an experience report, developed from an extension project carried out with a group of ten coordinators of Youth and Adult Education (EJA) in a municipality of the metropolitan region of Florianópolis (SC-Brazil), during the years 2016 and 2017. It was referenced in authors such as Lourau (1995; 2004), Lapassade (1983), Guirado (2004) and Machado and Sayão (2017). The intervention had as methodological device the Institutional Service (Plantão Institucional) (Lerner, Fonseca \& Machado, 2014). It was held on a team meeting day with the Nucleus coordinators and was held once a month, with about three or four meetings per semester. The number of meetings varied due to the demands and specific situations that occurred during the course of the work. The activities were carried out at the Psychological Attention Service of the Federal University of Santa Catarina (SAPSI) and lasted from one hour and a half to two hours and had an average of six to eight coordinators per meeting. The results identified that the coordinators placed themselves in a place of protagonism in relation to the EJA as a pedagogical and formative device, being taken as responsible for the implementation and accomplishment of its objectives. They encountered, however, many times with organizational and pedagogical difficulties while carrying out the work. Overproduction emerged as a resource to deal with these difficulties, through engagement and militancy.
\end{abstract}

Keywords: Youth and adult education; Institutional Psychology; Institutional overtime.

\section{Introdução}

A Educação de Jovens e Adultos (EJA) está presente na Lei de Diretrizes e Bases da Educação Nacional de 1996 (LDB), que institui, em seu artigo 37, que ela “...será destinada àqueles que não tiveram acesso ou continuidade de estudos no ensino fundamental e médio na idade própria" (Brasil, 2005, p.19). A EJA constitui uma forma de educação fundamental ofertada a adultos e jovens que tenham no mínimo quinze anos de idade, ou que não tenham completado a escolarização regular na idade prevista pela legislação.

Apesar de prevista na LDB e de ter mais de vinte anos desde sua implantação como política pública, a EJA tem apresentado, ao longo desses anos, inúmeros desafios. Pierro, Jóia e Ribeiro (2001) e Berger (2013) apontam que há um processo de juvenilização da educação de jovens e adultos em centros urbanos, fazendo com que essa seja pressionada pelas necessidades do mundo do trabalho e tornando a modalidade uma forma de "aceleração de estudos" para jovens que, de alguma maneira, tiveram um desempenho escolar abaixo do desejado. Além disso, Rummert e Ventura (2007) e Rummert (2007) apontam que a EJA se tornou uma forma de educar jovens que se encontram em uma situação de vulnerabilidade social e que se atrasaram no processo de escolarização. 
Rodrigues, Agostinho, Gesser e Oltramari (2014) analisam as consequências desse processo de "fracasso" dos estudantes que voltam à EJA para retomar os seus estudos. Esses estudantes encontram dificuldades, principalmente devido à fragilidade que apresentam em relação ao seu autoconceito, atrelado ao seu histórico de insucesso escolar.

Face a tais desafios, foi realizada uma parceria entre a Universidade Federal de Santa Catarina e a Coordenadoria de Educação de Jovens e Adultos de um Município da Região Metropolitana de Florianópolis (SC). Essa parceria teve início em 2012 com estágios curriculares em Psicologia Escolar em Núcleos de Educação de Jovens e Adultos daquele município.

A partir de algumas reuniões de avaliação, realizadas com o coordenador geral da EJA e o Laboratório de Psicologia Escolar e Educacional (LAPEE) do Departamento de Psicologia da Universidade Federal de Santa Catarina, resolveu-se iniciar uma série de reuniões sistemáticas com os coordenadores de núcleos de EJA. As reuniões aconteceram uma vez por mês e envolveram os coordenadores de núcleos de EJA do município. A rede de educação do município em questão possui Núcleos e esses, em alguns casos, organizam-se através de Polos. Ou seja, um Núcleo pode coordenar Pólos que são localizados em bairros. Cada Núcleo tem um coordenador, assim como um grupo de professores que atua nos diversos Polos do Núcleo.

A perspectiva teórica do trabalho realizado foi a da Análise Institucional e a orientação metodológica foi a do Plantão Institucional. Este é um dispositivo metodológico que tem como objetivo trabalhar especificamente com uma equipe o reconhecimento da pertinência dos conflitos, dilemas e estereotipias presentes no grupo e criar condições para sua tematização. Segundo
Machado \& Sayão (2017), ele tem por objetivo "incidir, principalmente, sobre as representações, as crenças e os valores que se materializam nas formas de agir e pensar" (p.159). Com isso foi possível analisar as compreensões que esses profissionais possuem de seus alunos, de seus fazeres e ações, do agrupamento a que pertencem, bem como das institucionalidades das quais participam.

Segundo Lerner, Fonseca, Sayão e Machado (2014), o Plantão Institucional propõe um compartilhamento de experiências e a produção de reflexões sobre uma situação dada, possibilitando estratégias que auxiliem no seu enfrentamento, considerando o conjunto da situação e sua complexidade. Buscou-se, com o Plantão Institucional, estabelecer uma estratégia de trabalho que utilizasse a dialogicidade produzida a partir das reflexões expressas pelos sujeitos que compuseram o grupo, para pensar novas práticas de atuação.

As teorias institucionalistas, de forma geral, compartilham como pressuposto "a necessidade de se levar em conta, a fim de compreender o indivíduo e suas manifestações coletivas, as mediações entre as estruturas sociais e os comportamentos individuais" (Théret, 2003, p. 225). Nessa denominação agrupam-se perspectivas teóricas bastante diferentes, como a Psico-higiene de Bleger (1984), a Socioanálise de Lourau (1995, 2004) e Lapassade (1983) e a Esquizoanálise de Deleuze e Guattari (Deleuze \& Guattari, 2011). Neste trabalho, utilizamos conceitos e categorias dessas três perspectivas teóricas, preocupados mais com as possíveis complementaridades entre seus conceitos e categorias de análise do que com suas incongruências teóricas. De forma geral, as teorias em questão compartilham o entendimento de que as práticas sociais são reproduzidas através de um ocultamento de seus significados. A explicitação desses 
significados ocultados é o principal objetivo da Análise Institucional. Além disso, compartilham o entendimento de que o instituído, as práticas sociais objetivadas através das organizações, pode ser compreendido criticamente, problematizado e transformado por meio de processos instituintes, constituidores, por sua vez, de novas institucionalidades. Portanto, o objetivo do trabalho desenvolvido tendo como recurso metodológico o Plantão Institucional foi o de, através das produções do próprio grupo, oportunizar a produção de novos significados e sentidos sobre o grupo e a EJA, buscando transformar suas práticas e encontrar respostas para seus desafios.

\section{Pressupostos da Análise Institucional}

Para a perspectiva institucionalista, a sociedade é formada por diversas instituições que se interpenetram e se articulam, lógicas que objetificam os valores abstratos da sociedade e regulam a atividade humana. Elas são concretizadas e repercutem na realidade social através das organizações. As organizações têm o seu sentido dado pelas instituições (Baremblitt, 1994). Para Georges Lapassade (1983), em um âmbito mais próximo à vivência concreta e cotidiana das dimensões institucional e organizativa das relações sociais, estão os grupos. Instituições, organizações e grupos constituem, então, do abstrato para o concreto, âmbitos diferenciados da vida social (Guirado, 2004).

Esses três níveis da realidade social estão presentes de maneira concomitante em cada vivência social, sendo os grupos formados pelos círculos cotidianos de convivência, a organização pelas normas jurídicas, as relações hierárquicas, os processos burocráticos, os papéis sociais e a divisão formal do trabalho. A instituição, por sua vez, diz respeito às lógicas da ação social que sobredeterminam os demais níveis sociais. No trabalho realizado, o grupo de coordenadores dos núcleos de EJA concretizam tanto a institucionalidade da educação de jovens e adultos, ou seja, seus princípios, valores e lógicas de ação, quanto a sua organização, o que envolve o conjunto dos elementos organizacionais que lhe são necessários, inclusive as relações burocráticas entre papéis e funções e suas hierarquias.

As teorias institucionalistas diferenciam dois momentos/processos interdependentes: o instituído e o instituinte. O primeiro diz respeito àquilo que está cristalizado nas relações sociais, estabelecido e fixo, concretizado pela organização, seus estabelecimentos, normas e procedimentos. O segundo é o movimento de mudança das relações já instituídas a fim de criar novas formas de se relacionar e novos processos organizativos (Guirado, 2004). Para René Lourau (2004), o instituído é "a ordem estabelecida, os valores, os modos de representação e de organização considerados normais" (p. 47). Já o instituinte, a capacidade de inovação. Considerando sua institucionalidade e seu caráter organizativo, todo grupo realiza, em alguma medida, as contradições entre o que está instituído e os movimentos instituintes.

Um dispositivo importante para a perspectiva institucionalista são os analisadores: ocorrências na materialidade da vida social que revelam cristalizações, impedimentos, injunções e contradições que evidenciam os estereótipos e lógicas instituídas presentes em um determinado contexto. Para Lourau (2004, p. 303), o analisador é "aquilo que permite revelar a estrutura da organização, provocá-la, forçá-la a falar”. Os analisadores evidenciam fortemente as contradições entre o instituído e o instituinte, sendo "porta-vozes dos conflitos em assídua oposição ao harmônico e ao estático acalentados pela instituição" (Rossi \& Passos, 2014, p. 47), ou seja, são as "ferramentas" pelas quais são explicitadas formas instituídas para que se possa gerar mudança. É a partir da escolha de um deles que se constrói a linha de raciocínio e 
argumentação da Análise Institucional. Ainda segundo os autores, o analisador explicita e permite uma compreensão da realidade institucional, o aparecimento de um dado real da instituição que, tirado da normalidade institucional, pode ser colocado em discussão e análise. Ele deve ser considerado em dois momentos: o primeiro, que passa pela realização da análise, e o segundo, que se dirige para a intervenção. Desse modo, ele pode servir para problematizar um acontecimento e/ou servir como um dispositivo de mudança (Rossi \& Passos, 2014).

Para Bleger (1984), as instituições e seus aparatos organizativos ${ }^{1}$ constituem parte da organização subjetiva da personalidade, na medida em que oferecem suporte e apoio e servem como elemento de segurança, de identidade e de inserção social. A Psicologia Institucional procura investigar e desenvolver relações entre indivíduos e instituições, visando evidenciar as cristalizações e estereotipias dessas relações que implicam, por extensão, a estereotipia da personalidade. Esta revela-se pelos impedimentos (explícitos ou velados) de emergência no grupo dos conflitos e dilemas. É a expressão desses conflitos e dilemas que torna possível a transformação institucional e o desenvolvimento das personalidades. A estereotipia é, justamente, "uma das defesas institucionais frente a um conflito" (Bleger, 1984, p. 52). Para esse autor, o problema é anterior ao conflito e se constitui como uma circunstância disjuntiva frente à qual é necessário tomar uma direção em um sentido comum. O conflito surge quando pessoas no grupo assumem e encarnam orientações distintas. Já o dilema surge quando essas diferentes orientações se apresentam como inconciliáveis e a eliminação das posições diferentes aparece como única opção. O dilema é, portanto, uma condição extrema do conflito.
Outros dois conceitos importantes para a Psicologia Institucional são os de implicação e de sobreimplicação, ambos propostos por René Lourau (1995, 2004). Para o autor, a implicação se dá de acordo com a qualidade das relações estabelecidas entre a pessoa e a instituição, a organização e o grupo. A análise da implicação revela os vínculos naturalizados entre a pessoa e os processos institucionais, organizacionais e o grupo do qual faz parte. Implicar-se sem análise, decorrendo daí um sobretrabalho, é compreendido como sobreimplicação. Sobreimplicar é, então, "um movimento intencional pelo qual nos engajamos na instituição" (Romagnoli, 2014, p.48), apresentando-se como uma implicação excessiva, não analisada.

\section{Método}

O relato de experiência aqui descrito foi resultado de um projeto de extensão universitária, desenvolvido entre os anos de 2016 e 2017. Ele foi realizado uma vez por mês, com cerca de três ou quatro encontros por semestre. O número variou devido às demandas e situações específicas que se apresentavam ao longo do andamento do trabalho, tais como reuniões extraordinárias, audiências com pessoas da gestão, eventos e ainda greves que alteravam a rotina dos coordenadores de Núcleo. Os encontros aconteciam em um dia de reunião de equipe de trabalho, ou seja, em horário e dia agendados previamente como atividade de reunião de trabalho, sempre no SAPSI, Serviço de Atenção Psicológica da Universidade Federal de Santa Catarina, e duravam cerca de uma hora e meia ou duas horas. Esse formato de trabalho iniciou em 2015. No começo, eram organizados com uma pauta prévia e desenvolvida nos momentos seguintes. Como muitas vezes o foco das discussões variava conforme as demandas

\footnotetext{
1 Bleger não faz, propriamente, uma distinção entre instituições e organizações, tomando-as, inclusive, como equivalentes.
} 
apresentadas pelo grupo, a estratégia foi modificada. Passou-se a construir a pauta com os participantes para, a partir deles, problematizar as práticas desenvolvidas pelo grupo. Todos os cuidados e compromissos éticos em relação à intervenção e suas possibilidades de comunicação foram informados e garantidos pelos interventores aos participantes $^{2}$.

Os encontros iniciavam com uma retomada das discussões anteriores. Uma das temáticas recorrentes com os coordenadores foi a da perspectiva metodológica da Pesquisa como Princípio Educativo. A Pesquisa como Princípio Educativo orienta as práticas pedagógicas da EJA no município e está, inclusive, prevista em seus documentos. A proposta é tornar a pesquisa como parte fundante da produção do conhecimento, não dicotomizando teoria e prática (Oliveira, 2008). Existem alguns princípios para que isso aconteça. O primeiro deles é o interesse do estudante pelo assunto por ele escolhido. O segundo é que se deve pensar em problemáticas, perguntas a serem respondidas, e não em temas de pesquisa que geralmente viram cópias por parte dos estudantes.

Como recurso metodológico da EJA, é importante que a pesquisa tenha um foco, para não haver dispersão entre os estudantes, e que os diversos conhecimentos trabalhados estejam relacionados. A pesquisa é algo que pode ser realizado por todos, em qualquer idade. Ela não pressupõe um conhecimento prévio, ela não pressupõe pré-requisitos. Como fundamento desse princípio metodológico, considera-se que a relação entre professor e aluno deve ser

\footnotetext{
${ }^{2}$ Por se tratar de um Projeto de Extensão, a atividade não foi submetida ao Comitê de Ética. Apesar disso, todos os participantes estavam cientes e conformes de que a atividade teria também como resultado sistematizações e comunicações acadêmicas específicas e que, em relação a isso, os direitos de anonimato, sigilo, confidencialidade e de poder se retirar da participação a qualquer momento estavam garantidos pelos interventores.
}

descentralizada e relacional. Estudantes e professores constituem um coletivo que trabalha de forma mediada para que o estudante consiga alcançar e produzir o conhecimento a partir de sua pesquisa.

Nessa perspectiva, os conteúdos não são uma lista fixa. Eles seguem um fluxo muito próprio do interesse e do foco da pesquisa do estudante. Assim, eles vão surgindo à medida que a pesquisa vai se tornando complexa e demandando mais conhecimentos. A ideia é que o conhecimento se relacione de forma orgânica com $o$ problema a ser respondido pelo estudante e, assim, faça sentido para ele. Isso faz a pesquisa não ser "disciplinar", pois os problemas da vida cotidiana não se apresentam separados e distintos.

Outra questão que surgiu com destaque nos debates do grupo foi a importância do planejamento e da avaliação. O planejamento enfatiza o papel do professor em orientar o estudante no desenvolvimento da pesquisa e não meramente no planejamento de aulas. Assim, o educador mediará os processos elaborados pelo estudante. Dessa forma, o planejamento vai acompanhando o estudante na trajetória de sua pesquisa. Através do acompanhamento realizado pelo planejamento, os mediadores podem avaliar o percurso do estudante. "Avalia-se pelo percurso realizado pelas partes - pelo percurso e pelo resultado, pelo produto e pelo processo" (Oliveira, 2008, p.41).

Nos encontros com os coordenadores ficou evidente que um aspecto importante do projeto político pedagógico da EJA é a 
militância. A militância é entendida nos documentos que orientam a prática dos coordenadores a partir da visão do professor como um transformador da realidade em que se encontra (Gallo, 2003). O professor é visto não apenas como aquele que vislumbra novas possibilidades para o fazer pedagógico, mas como quem se atreve, vivendo e compreendendo a realidade de seus alunos para a transformação dessa realidade a partir de uma construção coletiva.

A intervenção realizada tomou como analisador, num primeiro momento, as possíveis cristalizações e estereotipias encontradas pelo grupo no contexto da Educação de Jovens e Adultos. Para tanto, foi pedido ao grupo para identificar um evento, situação ou fato que apontasse em relação à EJA um conflito ou dilema. Ou seja, pediu-se para o grupo escolher um analisador abrangente para, a partir dele, constatar possíveis cristalizações e estereotipias institucionais. $\mathrm{O}$ grupo apontou uma série de situações que evidenciaram a violência na escola contra professores e estudantes. As situações de violência estavam presentes em três diferentes âmbitos: 1) na sociedade e na comunidade, associadas ao preconceito, marginalização e exclusão social que caracterizam o público atendido pela EJA; 2) na organização escolar, sobre como a EJA é, de certa forma, secundarizada pela Secretaria e pelas escolas, e 3) no cotidiano, na relação direta muitas vezes conflituosa com os alunos. Foram, então, apresentadas as seguintes perguntas, respondidas e problematizadas pelo grupo: "No contexto em análise, o que temos de estereotipia e cristalizado em relação a esses analisadores?"; "O que temos de novo, de criativo, inusitado, em relação aos analisadores?"; "Como o estereotipado encontra na organização o seu respaldo, a sua

\footnotetext{
${ }^{3}$ As frases entre aspas sem indicação de autor referemse a afirmações feitas pelos coordenadores ao longo dos encontros.
}

força?"; "Como o novo encontra (ou pode encontrar) na organização o seu respaldo?”.

Utilizando aqui a noção de analisador construído (Baremblitt, 1994), pediu-se para que cada participante elaborasse uma frase, tendo como referência as situações apontadas pelos analisadores espontâneos anteriores e a diferenciação feita entre os âmbitos comunidade, organização escolar e cotidiano. Após a elaboração e apresentação das frases, fez-se a reflexão no grupo, sobre contradições, conflitos ou impasses que elas, de alguma forma, poderiam identificar destacando, porém, as seguintes questões, colocadas novamente ao grupo: "Quem emite a fala?"; "Com qual intenção?”; “ O que ela revela?”. Justamente, a análise das reflexões feitas pelo grupo permitiu evidenciar, para além das estereotipias institucionais presentes, os processos de sobreimplicação que produzem e mantêm tais estereotipias.

\section{Resultados e Discussão}

Em um primeiro momento, as análises tiveram como foco o que os coordenadores consideraram como o ponto de vista dos estudantes sobre a EJA. Uma primeira fala foi identificada como comum entre os alunos: "Gostaria de ter matérias: matemática, português e geografia". Para alguns dos coordenadores de EJA, isso mostrava uma insatisfação com os processos de ensino; outros, de forma complementar, apontaram que os alunos estavam "questionando a metodologia"3, ou seja, o princípio educativo da EJA, mas que estavam também "em busca do conhecimento". Esse possível questionamento dos alunos sobre os princípios metodológicos da EJA surgiu como um ponto de tensão no grupo. Os coordenadores defenderam os princípios metodológicos, pois fazem parte do projeto político da EJA. No 
momento dessa discussão, surgiu certo desconforto no grupo devido a falas muito frequentes sobre um "não entendimento" do princípio educativo por parte dos estudantes. A defesa da Pesquisa como Princípio Educativo apareceu, então, como uma primeira estereotipia para o grupo cujo questionamento constituiu, também, um dilema.

Um dos participantes apontou que isso indicava que os discentes desejavam voltar para uma "zona de conforto" (sic), visto que o método difere do processo educacional tido como "tradicional". Em uma das falas no grupo, um dos coordenadores revelou que os estudantes lhes dizem que deveria ter mais oficinas, apontando que, apesar dos questionamentos, há o interesse em aprender, ainda que de forma mais frequente esse interesse não esteja vinculado aos adolescentes e sim aos participantes mais velhos. Aqui, as diferenças entre os discentes, principalmente em relação às faixas etárias, foram percebidas como um problema. Por exemplo, uma das coordenadoras apontou que os interesses às vezes não são comuns. Essa diferença cria atritos no interior das salas de aula. A diversidade de idade tem sido uma questão de discussão recorrente na literatura, pois ao mesmo tempo que a EJA foi constituída para pessoas que não tiveram possibilidade de escolarização ao tempo correto, existe uma juvenilização cada vez maior nas salas de aula (Pierro, Jóia \& Ribeiro, 2001; Berger, 2013).

Outro ponto abordado pelos participantes do grupo foi a necessidade de acolhimento dos estudantes. Muitos dos envolvidos nessa modalidade de educação decorrem de um processo de marginalização do processo de educação (Rummert \& Ventura, 2007; Rummert, 2007). Todos os coordenadores foram sensíveis a essa questão. Por exemplo, as falas: "acho que os estudantes precisam de alguém para ajudar" e "professora, eu preciso que alguém me diga o que fazer, eu não sei o que fazer", evidenciam algo já apontado pela literatura sobre um contato muito próximo do educador com a fragilidade psicossocial dos discentes (Rodrigues, Agostinho, Gesser \& Oltramari, 2014).

Muitas questões, porém, vão além das responsabilidades pedagógicas da escola. Em determinados momentos, o grupo conseguiu refletir sobre a complexidade de alguns fenômenos que extrapolam suas obrigações. Surgiram discursos sobre "ajudar esses estudantes", que foram marginalizados em seus processos educacionais e agora necessitavam, através da EJA, reconduzir suas trajetórias escolares para alcançar a formação desejada. Algumas vezes a expressão "recuperar o tempo perdido" foi usada, compreendendo, porém, que esses percursos não são lineares, não se "recuperam" e apresentam consequências delicadas devido ao distanciamento do sucesso escolar. Havia, no entanto, um entendimento de que podem ser ressignificados pelo sujeito. Alguns relatos, pontuais, indicavam situações de êxito pela passagem do aluno pela EJA. Na maior parte das falas, foi recorrente a referência de que a formação de professores da EJA requer um cuidado muito grande, que vai além de uma preocupação pedagógica, o que tem sido, em grande parte, apontado na literatura sobre Educação de Jovens e Adultos (Soares \& Pedroso, 2016).

Outro ponto trazido pelos participantes foi a identificação, entre os professores, de um discurso sobre a falta de respeito por parte dos estudantes. Segundo eles (coordenadores), os professores expressam, com certa frequência, uma preocupação sobre a falta de respeito e os comportamentos inadequados dos discentes: "Eles (os estudantes) têm que se comportar/respeitar". Esse desrespeito por parte dos alunos levaria os professores a assumir determinadas posturas. A expressão "Sou professor, não sou assistente social" ilustra essa demarcação sobre as diferenças de papel e de implicação em relação ao trabalho realizado. Para os coordenadores, isso, de certa 
forma, é tomado como uma "não implicação". Os participantes do grupo revelaram que a frase "Sou professor, não sou assistente social" expressava um acúmulo de atividades da EJA. Foi apresentada a eles a hipótese de que talvez houvesse um descompromisso por parte dos que enunciam essa frase. Essa hipótese foi rapidamente rechaçada e não foi bem aceita pelo grupo. Para eles, no entanto, essa questão poderia revelar uma incapacidade de ação, de não estar ou se sentir preparado para tais atribuições e de um acúmulo de atividades. Ao longo das reflexões feitas pelo grupo, alguns coordenadores concordaram que isso também poderia expressar certo descompromisso. Há que se considerar, também, que muitas vezes os professores têm dificuldades para resolver ou encaminhar certas questões e deixam para outros resolvê-las. Foi problematizado que alguns têm dificuldades emocionais para lidar com determinadas questões. Por fim, discutiuse sobre o papel de professor. Ser professor seria estar preocupado com o estudante ou não? A partir das discussões, foi apontado que o docente tem função limitada na escola e que os demais conflitos deveriam ser resolvidos por outros órgãos e profissionais. A reflexão realizada pelo grupo pode, em parte, ser compreendida a partir dos conceitos de implicação e sobreimplicação. A implicação caracteriza um vínculo intrínseco entre o sujeito de um determinado contexto institucional e seu aparato organizativo. Na sobreimplicação esse vínculo é tão intenso que, apesar da força de suas exigências, não é percebido pelo sujeito (Lourau, 1995; Paulon, 2005; Romagnoli, 2014). Os coordenadores trazem alguns elementos que permitem situar a implicação dos professores com as atividades da EJA e, ao mesmo tempo, a não sobreimplicação.

\footnotetext{
${ }^{4}$ Vale ressaltar que na EJA há uma rotatividade muito grande de professores. Muitos deles são contratados anualmente em caráter temporário, por isso o trabalho dos coordenadores constantemente é o de receber professores que não conhecem a proposta pedagógica e que necessitam de orientação para trabalhar com ela.
}

O grupo em análise identificou entre alguns docentes uma fala que é apresentada da seguinte forma: "não vou perder meu tempo com quem não quer aprender". Para eles, a frase expressa uma justificativa, mas, antes disso, evidencia preconceito e "comodismo". Os coordenadores cobram ou estranham que o corpo docente não tenha a mesma implicação que eles. Pontuam que, de alguma maneira, eles são os responsáveis por "defender" a EJA, salvaguardando sua proposta política e seu princípio educativo. Por vezes a defesa, tanto do princípio educativo quanto de determinadas críticas a uma falta de compreensão sobre a realidade do educando, parece estar relacionada a uma sobreimplicação no que diz respeito ao seu próprio trabalho, projetando essa necessidade de sobreimplicação no outro, no caso, os professores.

Ainda sobre os professores, os participantes trouxeram a discussão sobre a Pesquisa como Princípio Educativo. Segundo eles, muitos docentes acabam não investindo, ou mesmo não sabendo como utilizar a pesquisa como princípio educativo, o que fragiliza o processo de ensinar e aprender em sala de aula. Isso explicaria, para alguns, por que os professores não conseguem "defender" a proposta pedagógica da EJA. Os coordenadores acabam tendo, também, a responsabilidade pela formação dos seus subordinados, muitas vezes ingressantes na EJA $^{4}$ sem experiência com a pesquisa como um princípio e recurso metodológico importante. Parece que aqui se tem outra justificativa para a sobreimplicação dos participantes do grupo.

Ainda em relação à formação de professores/as e ao planejamento, os coordenadores apontaram que alguns 
procedimentos são fundamentais para o bom andamento das atividades dos docentes na EJA, no entanto, nem sempre tais procedimentos parecem estar claros. Pode-se tomar como exemplo o princípio metodológico da pesquisa e a compreensão interdisciplinar dos conhecimentos. Algumas falas revelaram: "Porque ele [estudante] tem matemática, tem português, tem geografia. A questão é de como ele enxerga isso". Falando sobre o trabalho interdisciplinar, a ideia é que mais de um professor se ocupe pela mediação das pesquisas dos educandos. Essa discussão é fundamental, considerando a pesquisa como princípio educativo, pois a prática da investigação é, por excelência, interdisciplinar já que aborda de forma abrangente os problemas que constituem a realidade do estudante (Oliveira, 2008).

Localiza-se, então, uma dificuldade quanto ao planejamento por parte dos docentes: "A dificuldade é planejar na verdade, para orientar a pesquisa e [...] que os estudantes fiquem na aula porque daí eles têm algo para fazer. Vejo que os/as professores/as não têm o hábito de planejar". Ou ainda: "Para o professor não chegar na sala e dizer "não sei o que vou fazer hoje' como já ouvi por ai'. A necessidade de um trabalho integrado, principalmente devido a uma perspectiva pedagógica interdisciplinar, acaba exigindo um planejamento conjunto dos docentes que muitas vezes é percebido como um problema, pois, segundo os coordenadores, não ocorre como deveria.

Aqui, a fala de um dos participantes torna-se relevante: "a prática da pesquisa tem certa particularidade que não seria para todos". Ou seja, haveria algumas habilidades necessárias, quase como pré-requisitos, para os professores se envolverem com a EJA. Isto faria com que muitas vezes a pesquisa (ensinar o princípio educativo) não se tornasse acessível a todos. "O método não é para todos; tem que tomar cuidado para não estigmatizar [os professores]". Em relação a esse tema, outra coordenadora apontou a confiança no método como um princípio. Nesse caso, a fala veio no intuito de reforçar o que seria o princípio fundamental para conduzir os trabalhos na educação de jovens e adultos. Outros falaram que a EJA era um espaço de formação constante e que os docentes que não concordam com a perspectiva da EJA não conseguem ficar muito tempo. Assim, a Pesquisa como Princípio Educativo aparece como princípio metodológico fundamental, sendo a implicação com o princípio um referente identitário relevante para a coesão do grupo.

Alguns analisadores construídos trouxeram os desafios enfrentados pelos participantes. A frase proferida por um deles: "Nosso cotidiano escolar, nossas angústias, nossas impotências: exercício do diálogo, o caminho na busca do ambiente acolhedor e que saibamos conviver com as diferenças", indicava, ao mesmo tempo, uma queixa e uma defesa do trabalho. Apareceram, também, expressões como: "coordenador da EJA é tudo" e "o sujeito [o coordenador] precisa estar comprometido com o seu trabalho". Alguns reforçaram que muitas vezes o cargo de coordenador é muito exigente com quem o ocupa, pois supera as questões pedagógicas. Aqui, pode-se pensar sobre a demanda vivenciada por tais profissionais. Eles, ao mesmo tempo que reconhecem um nível de cobrança muito grande sobre si, impõem aos docentes algo similar. Novamente, evidenciase uma sobreimplicação, reproduzida nas relações entre gestores e subordinados, percebidos estes últimos geralmente como não sobreimplicados.

Outro desafio abordado nos encontros foi a estrutura física na qual trabalham. Isso surgiu na frase: "Nossa proposta pedagógica é acolhedoral flexível, mas a estrutura da escola e a representação desta para o estudante, não". Os coordenadores trouxeram a informação de que tinham a intenção de encontrar um local apropriado para a EJA, pois os núcleos se 
reúnem em espaços de outras escolas, no período da noite, não acontecendo suas atividades em um local próprio. Isso muitas vezes gerava tensão e problemas aos gestores, principalmente em relação aos diretores das escolas com quem o espaço é dividido e, também, em relação aos educandos.

Algumas falas dos participantes evidenciaram dificuldades enfrentadas entre os discentes, como, por exemplo, as relacionadas às diferenças geracionais. Eles disseram que escutavam: "pô, diretor, por que você fica com esses [estudantes] aí? Se fosse eu, mandava todo mundo embora" [fala de um educando ao professor de EJA]. Alguns coordenadores disseram até compreender quando isso era dito por um estudante, mas não se conformavam quando essa fala vinha de um docente. O estranhamento apontado fere um dos princípios mais caros aos coordenadores: o princípio do comprometimento com os educandos atendidos pela EJA. Para eles, um professor que se coloca através desse discurso não demonstra engajamento e não consegue ser um educador transformador da realidade, princípio que está presente em um documento muito citado pelos coordenadores (Gallo, 2003).

Algo que marcou a discussão do grupo foi o preconceito contra os alunos da EJA. Essa discussão foi um disparador de questões pessoais dos coordenadores. Quando solicitados a procurar características individuais que proporcionam uma identificação com o trabalho da EJA, eles trouxeram suas histórias pessoais, muitas delas de dificuldades e pobreza. Relataram o quanto a EJA teria para eles um aspecto de "militância", de transformação social através da educação. Estar na EJA remetia os coordenadores a uma perspectiva de tentar fazer algo para aqueles estudantes que se encontram em um contexto de extrema vulnerabilidade. Destacaram a importância da característica de seus pensamentos militantes para esse trabalho específico na EJA. Alguns lembraram que suas trajetórias acadêmicas iniciaram junto aos movimentos estudantis, apontando a universidade e esses movimentos como responsáveis por suas escolhas. Para Bleger (1984), as instituições são um suporte para a realização e o desenvolvimento da personalidade. Elas constituem uma estrutura de identificações que funciona como um "instrumento de equilíbrio e regulação da personalidade" (Bleger, 1984, p.55). A identificação com determinados referentes institucionais pode corresponder a uma satisfação pessoal na medida em que esses referentes são também pessoalmente relevantes. Haveria aqui uma correspondência identitária entre referentes coletivamente disponibilizados - a militância e o engajamento como uma característica intrínseca ao trabalho na EJA - e referentes advindos de valores e da trajetória pessoal (Naujorks \& Silva, 2016).

Alguns participantes apontaram que se identificam com os seus educandos, inclusive com a vulnerabilidade deles. Relataram que é necessário ter uma autenticidade com os alunos para estabelecimento de uma relação mais próxima. Ao fazer essa discussão, eles resgataram suas trajetórias pessoais e suas identificações com o trabalho, mobilizando-se emotivamente, inclusive. Nas discussões ficou muito presente que, para além de uma relação profissional, existe uma identificação militante com o trabalho, que os faz, de certa forma, exigir o mesmo dos professores com quem trabalham.

Ao longo do processo de intervenção realizado pelo Plantão Institucional, alguns pressupostos estiveram presentes: primeiro, a noção de que conflitos são constitutivos das relações grupais e que a aparente normalidade do grupo é algo que encobre os conflitos e produz estereotipia. A possibilidade da emergência do conflito evidencia, ao contrário, a maturidade do grupo, pois permite lidar com as diferenças e com a mudança. $\mathrm{O}$ grupo aparece, aqui, como sujeito da mudança. 
Procurou-se, ao longo dos encontros, explicitar os conflitos centrais percebidos pelo grupo em relação à EJA e quais as diferentes posições. Buscou-se, também, demonstrar as defesas e resistências frente às posições dos diversos membros em relação aos conflitos e dilemas e suas diferentes implicações. Isso direcionou a intervenção à análise das implicações e aos processos identitários que, no caso, sustentam a sobreimplicação.

\section{Considerações finais}

Diversos agentes, localizados de diferentes formas no contexto institucional, com percepções e intencionalidades diversas, encontram-se trabalhando e efetivam a EJA como uma estratégia e um dispositivo pedagógico e formativo. Os coordenadores colocam-se em um lugar de protagonismo em relação a esse processo, tomando-se como responsáveis pela implementação do método e pela efetivação de seus objetivos. Deparam-se, porém, com inúmeras construções organizacionais, com outros agentes (educadores, membros da burocracia municipal, etc.) e com os alunos. $\mathrm{O}$ engajamento e o compromisso com os alunos da EJA caracterizam o fazer pedagógico para além das relações de ensino-aprendizagem, centradas em determinados conteúdos. Esse envolvimento e esse empenho encontram sua correspondência nas trajetórias pessoais dos coordenadores e se realizam concretamente através da sobreimplicação. Esta, por sua vez, procura repor um conjunto de faltas: a suposta falta de engajamento dos professores, as dificuldades de realização do método, os impedimentos decorrentes da especificidade dos alunos, a falta de condições de trabalho de muitos dos professores. Assim, todas as responsabilidades parecem ficar depositadas nos próprios coordenadores.

Em vários momentos, durante os encontros, foram levantadas questões que apontavam para as dificuldades oriundas do contexto organizacional, como a Prefeitura e a Secretaria de Educação. Os desafios organizacionais e as indagações trazidas pelos alunos foram percebidos como fortes empecilhos para a efetivação do trabalho. Porém, uma das questões mais difíceis para os coordenadores dizia respeito ao empenho em implementar e fazer funcionar o princípio político/pedagógico da Pesquisa como Princípio Educativo, por resistência ou oposição, tanto por parte dos educandos quanto dos professores. Constantemente se reafirmava a importância desse princípio e se interditava qualquer questionamento a ele. A defesa da modalidade vinha ou com uma desqualificação daqueles que a criticavam, justificada por eles como um desconhecimento, ou uma justificativa, alertando que era algo com que não estavam acostumadas, por isso a resistência.

A intervenção trouxe assuntos difíceis para a análise do grupo e colocou em contradição princípios caros aos coordenadores, principalmente para aqueles fortemente identificados com suas trajetórias pessoais, o que gerava, certamente, forte resistência. Esse movimento parece compreensível. Uma modalidade cuja estrutura física depende de outras escolas e que tem entre seus profissionais uma rotatividade muito grande, quase sempre contratados sem ter uma experiência em EJA, encontra nos seus valores e princípios o que há de mais importante para sua efetivação. Justamente esses valores e princípios permitem aos gestores trabalhar de uma forma engajada e militante, questionadora da concepção tradicional de ensino e que, por vezes, é questionada por educandos e alguns professores. A defesa do princípio político/pedagógico parece uma estratégia para reforçar o trabalho e manter a coesão de grupo.

No fim do trabalho foi importante evidenciar que ainda existia, nos coordenadores da EJA, a esperança de fazer um mundo diferente, transformando-o através da 
educação. São profissionais que mantiveram um engajamento contínuo, em um cotidiano e rotineiro fazer e refazer de suas práticas. Defendiam aquilo em que acreditam, capacitando outros profissionais com dificuldades sobre como proceder em relação a uma metodologia que pouco conhecem. Intercediam junto aos estudantes para que aprendessem, mesmo que esses muitas vezes desacreditassem, não necessariamente no método, mas na própria possibilidade de sucesso escolar. Muitos deles estavam na EJA por já apresentarem um processo de fracasso, provocado exatamente pela escola que frequentaram anteriormente e à qual continuavam atrelados. Esses coordenadores evidenciaram que ainda acreditam que a educação tem a capacidade de se opor não apenas às agruras da ignorância, mas também à incapacidade de se indignar com as desigualdades.

\section{Referências}

Baremblitt, G. (1994). Compêndio de Análise Institucional e outras correntes. Rio de Janeiro: Rosa dos Tempos.

Berger, D. (2013). Trajetórias Territoriais dos Jovens da EJA. Congresso de Educação Básica, (pp. 1-11). Florianópolis.

Bleger, J. (1984). Psico-Higiene e Psicologia Institucional. Porto Alegre: Artmed.

Brasil. (2005). Lei de Diretrizes e Bases. Brasília: Ministério da Educação.

Deleuze, G. \& Guattari, F. (2011). O AntiÉdipo. Capitalismo e esquizofrenia (2a ed.). São Paulo: Editora 34.

Gallo, S. (2003). Deleuze \& Educação. Belo Horizonte: Autêntica.

Guirado, M. (2004). Psicologia Institucional. São Paulo: EPU.

Lapassade, G. (1983). Grupos, organizações e instituições. Rio de Janeiro: Francisco Alves.

Lerner, A., Fonseca, P. S., \& Machado, A. (2014). Plantão institucional: uma modalidade de intervenção face ao malestar contemporâneo na educação. Estilos da Clínica, 19, 199-208. Recuperado de http://pepsic.bvsalud.org/scielo.php?script= sci_arttext\&pid=S1415$71282014000100013 \& \ln g=p t \& t \operatorname{lng}=\mathrm{pt}$

Lourau, R. (1995). A análise institucional. Petrópolis: Vozes.

Lourau, R. (2004). René Lourau. Analista institucional em tempo integral. São Paulo: HUCTEC.

Machado, A.; \& Sayão, Y. (2017). Plantão institucional em tempos difíceis: uma prática psi no campo da educação. In A. M. Machado, A. B. C. Lerner, \& P. F. Fonseca (Orgs.), Concepções e proposições em Psicologia e Educação (pp. 159-172). São Paulo, SP: Blucher.

Naujorks, C. \& Silva, M. (2016).

Correspondência identitária e engajamento militante. Civitas, 16(1), 136-152. doi: $\underline{10.15448 / 1984-7289.2016 .1 .18139}$

Oliveira, G. M. (2008). A pesquisa como princípio educativo: construção coletiva de um modelo de trabalho. Estrutura, Funcionamento, Fundamentação e Prática na Educação de Jovens e Adultos (pp. 3743). Florianópolis: Prefeitura Municipal de Florianópolis.

Paulon, S. M. (2005). A análise de implicação com ferramenta na pesquisa-intervenção.

Psicologia \& Sociedade, 17(3), 18-25. doi: 10.1590/S0102-71822005000300003

Pierro, M. C., Jóia, O., \& Ribeiro, V. M. (2001). Visões da educação de jovens e adultos no Brasil. Cadernos CEDES, 21(55), 58-77. doi: 10.1590/S010132622001000300005

Rodrigues, G. T., Agostinho, S. C., Gesser, M., \& Oltramari, L. C. (2014). Psicologia e educação de jovens e adultos: um desafio em construção. Psicologia Escolar e Educacional, 18(1), 181-184. doi: $10.1590 /$ S1413-85572014000100020

Romagnoli, R. (2014). O conceito de implicação e a pesquisa-intervenção institucionalista. Psicologia \& 
Sociedade, 26(1), 44-52. doi: 10.1590/S0102-71822014000100006

Rossi, A., \& Passos, E. (2014). Análise Institucional: revisão conceitual e nuances da pesquisa-intervenção do Brasil. Revista Epos, 5(1), 156-181. Recuperado de http://pepsic.bvsalud.org/scielo.php?script= sci_arttext\&pid=S2178700X2014000100009\&lng=pt\&tlng=pt

Rummert, S. M. (2007). A educação de jovens e adultos trabalhadores brasileiros no século XXI: O "novo" que reitera antiga destituição de direitos. Sísifo/Revista de ciências da educação (2), 29-45.

Recuperado de http://forumeja.org.br/sites/forumeja.org.br/ files/sisifo0203_rummert.pdf
Rummert, S. M., \& Ventura, J. P. (2007). Políticas públicas para educação de jovens e adultos no Brasil: a permanente (re)construção da subalternidade considerações sobre os Programas Brasil Alfabetizado e Fazendo Escola. Educar em Revista, (29), 29-45. doi: 10.1590/S010440602007000100004

Soares, L. J., \& Pedroso, A. P. (2016). Formação de educadores na educação de jovens e adultos (EJA): alinhavando contextos e tecendo possibilidades. Educação em Revista, 32(4), 251-268. doi: 10.1590/0102-4698161277

Théret, B. (2003). As instituições entre as estruturas e as ações. Lua Nova: Revista de Cultura e Política, (58), 225-254. doi: 10.1590/S0102-64452003000100011

\section{Dados sobre os autores:}

- Leandro Castro Oltramari: Professor do Departamento de Psicologia da Universidade Federal de Santa Catarina, Membro do Laboratório de Psicologia Escolar e Educacional (LAPEE) UFSC. Possui graduação em Psicologia pela Universidade do Vale do Itajaí (1997), mestrado em Psicologia pela Universidade Federal de Santa Catarina (2001) e doutorado em Interdisciplinar em Ciências Humanas pela Universidade Federal de Santa Catarina (2007). Tem experiência na área de Psicologia, com ênfase em Processos Grupais e de Comunicação, atuando principalmente nos seguintes temas: Psicologia da Educação, gênero e sexualidade.

- Carlos José Naujorks: Professor do Departamento de Psicologia da Universidade Federal de Santa Catarina. Doutor em Sociologia pela Universidade Federal do Rio Grande do Sul (2011), mestre em Sociologia Política pela Universidade Federal de Santa Catarina (1999), psicólogo pela Universidade Federal de Santa Catarina (1993). Membro do Laboratório de Psicologia Escolar e Educacional (LAPEE). Áreas de Atuação: Psicologia Social Crítica do Trabalho; Psicologia Institucional. Temas de interesse: Identidade; Engajamento; Clínicas do Trabalho; Psicologia Institucional; Movimentos Sociais. 